\title{
Blackface, Bullying and Freedom of Expression: What Legal Education Means for Law Student Welfare
}

\author{
Samuel V. Jones
}

Associate Dean and Professor of Law John Marshall Law School

\section{Abstract}

Today, law student safety is a serious but often missed objective in American law schools. According to a recent survey, the typical American family wants to know their law student is safe even more than they want their law student to acquire a firstrate legal academic experience. Despite the importance of law student mental health to student performance, and cultural objectives unique to legal education, law students are not only highly vulnerable to acquiring mental health challenges during law school but are prone to be overlooked, and perhaps blamed or condemned for their mental health challenges, albeit unintentionally. My work asserts that despite the chief objective of law schools being to educate knowledgeable, competent, legal professionals, and provide them with the necessary skills to resolve complex legal essentials for corporations and government, as well as advance social justice, and to promote equal treatment for all, inherent in the nature of legal education, is a seemingly widely accepted risk of compromising law student mental health. Relying on qualitative studies and journalistic reports, my work will demonstrate that law students experience high incidents of personal depression, anxiety, extreme sadness, loss of interest or desire, feelings of guilt or low self-esteem, disturbed sleep or appetite, low energy, poor concentration, and a myriad of other mental and physical calamities, all of which greatly exceeds that of the law faculty, and surpasses levels experienced by medical and graduate students at American schools of higher education. My work further acknowledges that law student anxiety and depression are inextricably linked to the rigorous academic demands of legal education. Still it argues and set forth that law student mental health is related to avoidable conditions and patterns in the law school environment that enable or fail to account for the law student's inexperience with coping with intense stress, emotional uncertainty, geographical isolation from loved ones, strained financial resources, poor job prospects, family strife, drug or alcohol abuse, homelessness, or lack of a culturally responsive learning environment. Granted, the legal profession is not for everyone. My work argues that law schools cannot turn a blind eye to the plight of law students as if no degree of accountability and responsibility lies with the law school. Indeed, law schools, albeit unintentionally, may be some of the chief investors in patterns of conduct that compromise the physical, emotional, and mental safety of law students. Recognition of a law school's duty to students, in my view, requires law schools to resist the rhetoric of self-exceptionalism. Law schools, have an obligation, reluctantly or not, to concretely curtail repeated patterns of professional abuse, neglect, dereliction of academic duties, social domination, and student exploitation, that are uniquely embedded in the culture of legal education. Simply put, law student safety needs, coupled with the intricacies and unforgiving consequences of today's 
competitive legal job market and high cost of legal education, warrant that law schools resist the impulses that prioritize institutional-preservation and subordinate student mental health under the guise of teaching students the harsh realities of the legal profession and preparing them for legal practice. My work argues that student physical, emotional, mental and academic safety should, and must become a critical component of legal education.

Keywords: Blackface, Bullying, Freedom of Expression, Legal Education Means, Law Student Welfare 